\title{
ESTRATÉGIAS FARMACOLÓGICAS PARA A TERAPIA ANTI-AIDS
}

\author{
Emerson Poley Peçanha*\# e Octavio A. C. Antunes \\ Instituto de Química, Universidade do Brasil, CT-Bl. A, Ilha do Fundão, 21945-970 Rio de Janeiro - RJ \\ Amilcar Tanuri \\ Instituto de Biologia, Universidade do Brasil, CCS-B1. A, Ilha do Fundão, 21945-970 Rio de Janeiro - RJ
}

Recebido em 19/7/01; aceito em 1/4/02

\begin{abstract}
PHARMACOLOGICAL STRATEGIES FOR ANTI-HIV THERAPY. The replicative cycle of HIV presents several events. The proteins involved in these events can be anticipated as pharmacological targets, aiming to the development of anti viral agents. Presently, there are fifteen commercially available anti-HIV drugs, which act at substrate binding site of reverse transcriptase (zidovudine, didanosine, zalcitabine, stavudine, lamivudine and abacavir), at a non-substrate binding site of reverse transcriptase (nevirapine, delavirdine and efavirenz), or by inhibiting HIV protease activity (saquinavir, ritonavir, indinavir, nelfinavir, amprenavir and lopinavir). The present review focus both on these established classes of drugs and on new classes of compounds acting on other virus specific steps.
\end{abstract}

Keywords: HIV life cycle; AIDS therapy; perspectives in AIDS therapy.

\section{INTRODUÇÃO}

A síndrome da imunodeficiência adquirida (AIDS) é uma doença pandêmica que tem como agente etiológico o vírus HIV (Human immunodeficiency virus), um retrovírus pertencente à subfamília Lentivirinae. Retrovírus são vírus que contém RNA ${ }^{1}$. No mundo inteiro, estima-se que 33,4 milhões de pessoas (32,2 milhões de adultos e 1,2 milhões de crianças com menos de 15 anos) estão vivendo com HIV/AIDS. No Brasil, de 1980 até agosto de 1998, foram assinalados 140.362 casos de AIDS, com 71.733 óbitos conhecidos (Ministério da Saúde-Brasil, 1999). Através de inquéritos sorológicos feitos pelo Ministério da Saúde estima-se a existência de 536.000 pacientes infectados pelo HIV em nosso país.

$\mathrm{O}$ alvo principal do vírus HIV durante a infecção é o linfócito T $\mathrm{CD}^{+}$. Por esta razão, o quadro clínico da AIDS é caracterizado em função da contagem sangüínea de linfócitos $\mathrm{T}$ CD4+ no indivíduo infectado com o HIV, e da caracterização das condições clínicas relacionadas à infecção com o HIV².

Os HIV estão relacionados a lentiviroses animais com base em critérios patológicos, morfológicos e genéticos. $\mathrm{O}$ mapa genético do HIV mostra três regiões principais: a região gag, que codifica as proteínas estruturais internas p17 (MA), p24 (CA), p7 (NC) e p6, a região pol, que codifica a protease (p11, PR), transcriptase reversa (p66/p51, $\mathrm{RT}$ ) e integrase (p31, IN) e, finalmente, a região env, responsável pela codificação das proteínas do envoltório, gp120 (SU) e gp41 (TM) ${ }^{3}$. O genoma do HIV-1 codifica ainda seis outras proteínas acessórias, sendo duas (tat e rev) relacionadas com a regulação da expressão gênica ${ }^{3}$.

Internamente às glicoproteínas de superfície (gp120 e gp41) e à membrana de lipídios, a proteína p17 completa o envelope viral. Já o cerne ou capsídeo viral é envolvido pela proteína gag p24 . No interior do capsídeo há duas cópias do RNA genômico de mono-fita (35S RNA) ${ }^{4}$ que, supostamente, existe na forma de uma ribonucleoproteína contendo transcriptase reversa (RT), Integrase (IN)

\footnotetext{
*e-mail: emerson@pharma.ufrj.br

\#Departamento de Pesquisa e Desenvolvimento Tecnológico, FarManguinhos, Fundação Oswaldo Cruz, Av. Brasil, 4365, Manguinhos, 21045-900 Rio de Janeiro - RJ
}

e a proteína p7 (NC) de ligação ao RNA. No interior do capsídeo encontram-se ainda as proteínas p6, Vif, Vpr e $\mathrm{Nef}^{3}$.

Apesar da característica mais marcante da infecção por HIV ser uma depleção seletiva de linfócitos $\mathrm{CD}^{+}$, macrófagos, monócitos e células de Langerhans, entre outras, são também susceptíveis à infecção por $\mathrm{HIV}^{4}$.

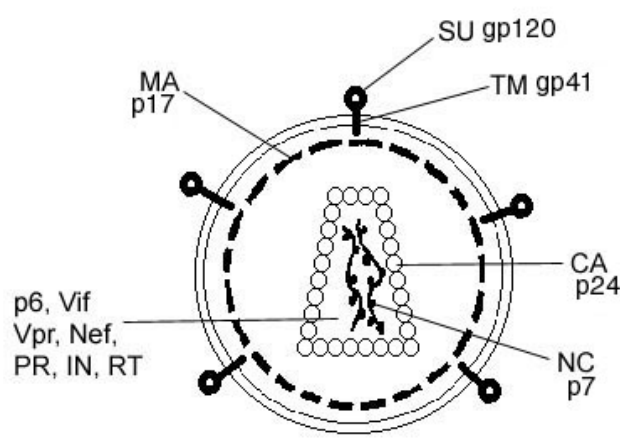

Figura 1. Morfologia do HIV

\section{CICLO DE REPLICAÇÃO DO HIV}

O primeiro passo para o início da infecção é a ligação da partícula viral a receptores específicos na superfície da célula alvo. No caso de retroviroses e outros vírus com envelope, a interação com o receptor celular é mediada por uma glicoproteína do envelope. A proteína responsável pelo reconhecimento do HIV por suas células alvo é a gp120 $(\mathrm{SU})^{5}$. O principal correceptor para HIV-1 é o CD4, uma proteína tipo imunoglobulina (Ig) expressa na superfície de células T e macrófagos primários $^{6}$. A proteína de 515 amino ácidos gp120 liga-se ao receptor CD4 com alta afinidade ( $\mathrm{Kd} \sim 4 \mathrm{nM})$ aparentemente através de uma região altamente conservada próxima à porção carboxi-terminal $(\mathrm{C}$ terminal) que compreende os resíduos 397-4397. Entretanto, apenas a interação gp120-CD4 não é suficiente para a entrada do HIV na célula alvo. Um grupo de receptores de quimiocinas (pertencentes à família 
dos receptores acoplados à proteína $\mathrm{G}$ ), que mobilizam cálcio intracelular e induzem quimiotaxia em leucócitos ${ }^{8}$, atuam como receptores essenciais ao reconhecimento da célula alvo ${ }^{9}$. As duas maiores classes de HIV-1, as que apresentam tropismo por células T (Ttrópico) e as que apresentam tropismo por macrófagos (M-trópico), diferem quanto aos receptores envolvidos no reconhecimento viral ${ }^{10}$. Os vírus M-trópicos, que não tem capacidade de formar sincítios, utilizam-se dos receptores CCR5 para a interação com a célula, enquanto os HIV-1 tipo T-trópico, formadores de sincítios, necessitam dos receptores CXCR $4{ }^{11}$. A alça V3 da proteína gp120 é a provável responsável pelo reconhecimento dos receptores e conseqüente tropismo celular, esta estrutura da gp120 parece ser exposta à interação com os receptores de quimiocinas após mudanças conformacionais decorrentes da interação inicial entre gp120 e CD4 ${ }^{12}$. Entretanto, a alça V3 não parece ser a única determinante na especificidade viral, uma vez que ela apresenta uma grande variação na sequiência de aminoácidos, mesmo em isolados de HIV-1 que apresentam o mesmo tropismo, e utilizam os mesmos correceptores ${ }^{13}$.

Após a ligação à membrana celular, a proteína gp120 dissocia-se da proteína gp41 (um trímero de um dímero) ${ }^{14}$, que passa por modificações conformacionais que promovem a fusão vírus-célula, permitindo a entrada do capsídeo na célula ${ }^{15}$. Um resíduo peptídico $\mathrm{N}$ terminal hidrofóbico, rico em glicina, presente na gp41 parece iniciar a fusão, enquanto a região transmembrana é importante tanto para a fusão quanto para a ancoragem da proteína Env na membrana viral ${ }^{16}$.

Após a fusão, o capsídeo do vírion é então desencapado em um processo que consiste na liberação no citoplasma do conteúdo do capsídeo, o RNA genômico e enzimas virais, o que se faz necessário para a etapa posterior, a transcrição reversa ${ }^{3}$. A transcriptase reversa (RT) promove a síntese de uma cópia de DNA de fita dupla, catalisando as reações de polimerização de DNA dependente de RNA e dependente de DNA, além de clivar a porção de RNA do híbrido RNA-DNA formado durante o processo (atividade ribonuclease H, RN) ${ }^{4}$. Seguindo-se a transcrição reversa, um complexo nucleoproteico, incluindo IN, MA e o DNA formado, é rapidamente transportado para o núcleo da célula hospedeira em um processo mediado pela Vpr, uma proteína de 96 amino ácidos ${ }^{17}$. A ação desta proteína permite o transporte do complexo nucleoproteico mesmo na ausência de quebra mitótica do envelope nuclear ${ }^{17}$. A ação de uma terceira enzima viral, a integrase (IN), resulta na integração estável do cDNA do genoma viral no DNA cromossômico através de várias etapas como endonuclese, transferência de fita, desintegração e ligação, estabelecendo um pró-virus e completando assim a fase pré-integrativa ${ }^{18}$.

Uma vez que o pró-virus é integrado no DNA hospedeiro, comporta-se como um gene celular residente. Para a maioria das retroviroses a expressão dos pró-virus integrados é governada exclusivamente por proteínas celulares ${ }^{4}$. Entretanto, a expressão gênica das retroviroses humanas é regulada adicionalmente por proteínas virais ${ }^{3}$. Os RNAs virais transcritos são expressos a partir do promotor localizado no 5' LTR ("long terminal repeat") ${ }^{19}$ e a proteína acessória Tat ("trans-acting transcription transactivator") aumenta consideravelmente a velocidade de transcrição ${ }^{20}$. Na ausência de Tat, as RNA polimerases são geralmente incapazes de transcrever sequiências maiores que algumas centenas de nucleotídeos. Ao contrário de ativadores de transcrição usuais, a Tat não se liga em sítios no DNA, mas sim a uma dobra na região 5' terminal do RNA em formação conhecida como TAR ("trans-activating response element")

O conjunto de RNAs transcritos, de tamanho genômico ou divididos, são então transportados para o citoplasma, onde serão então traduzidos, ou constituirão novas partículas virais em um processo regulado pela $\operatorname{Rev}^{22}$. A tradução citoplasmática dos mRNAs virais fornece as proteínas Vif, Vpr, Nef, além das poliproteínas gag e gagpol que serão processadas posteriormente em MA, CA, NC, p6, PR,
RT e IN ${ }^{4}$. As proteínas gp120 e gp41, presentes na membrana externa do HIV-1, são formadas a partir da poliproteína Env que, por sua vez é coexpressa com os receptores $\mathrm{CD} 4$ no $\mathrm{RE}^{4}$. A degradação dos receptores CD4 recém sintetizados, necessária ao transporte da Env até a membrana celular, é assistida pela proteína $\mathrm{Vpu}^{23}$.

A Vpu é uma proteína de 81 amino ácidos ativada após a fosforilação de Ser52 e Ser56 por uma proteína análoga à caseinacinase- $2^{17}$. Além de sua função na degradação de CD4, a Vpu promove a "downregulation" de proteínas de superfície celular da classe MHC I, que estão envolvidas no reconhecimento das células infectadas por linfócitos $\mathrm{T}$ citotóxicos ${ }^{24}$. A proteína parece ainda estimular a liberação de partículas virais ${ }^{23}$.

As modificações das poliproteínas pró-virais gag, gag-pol e env, recém sintetizadas envolve a miristolilação das duas primeiras e a glicosilação da $E^{25} v^{25}$. A adição de ácido mirístico fornece um domínio hidrofóbico necessário à interação com a membrana celular, facilitando a montagem do vírus ${ }^{4}$. Um fator relevante no ciclo de replicação do HIV é a atividade das poliproteínas formadas antes mesmo de sofrerem processamento proteolítico. A porção p17 da gag promove a agregação da gag e da gag-pol no citoplasma ${ }^{4}$, enquanto a p7 (NC) liga-se e carreia o RNA, iniciando assim a montagem do vírus ${ }^{26}$.

Os vírions são inicialmente montados próximo à membrana celular na forma de partículas imaturas compostas de um envelope glicoprotéico, RNA genômico e poliproteínas virais ${ }^{27}$. Após, ou durante o "brotamento", as partículas virais passam por uma modificação morfológica conhecida como maturação ${ }^{28}$. A maturação consiste na clivagem das poliproteínas gag e gag-pol pela protease viral (PR, p11), produzindo enzimas e proteínas estruturais do capsídeo ${ }^{27}$. O processamento proteolítico das poliproteínas ocorre apenas em um estágio avançado do ciclo de replicação, provavelmente em virtude de uma baixa atividade enzimática da protease não processada, requerendo assim altas concentrações de substrato, o que é alcançado apenas durante o "brotamento" 29 . Após uma hidrólise inicial, a protease liberada pode então exercer sua atividade máxima, processando de forma rápida as poliproteínas ${ }^{30}$. O processamento das poliproteínas no vírion completa o ciclo de replicação do HIV. Os vírions maduros são então capazes de infectar um linfócito adjacente ${ }^{4}$.

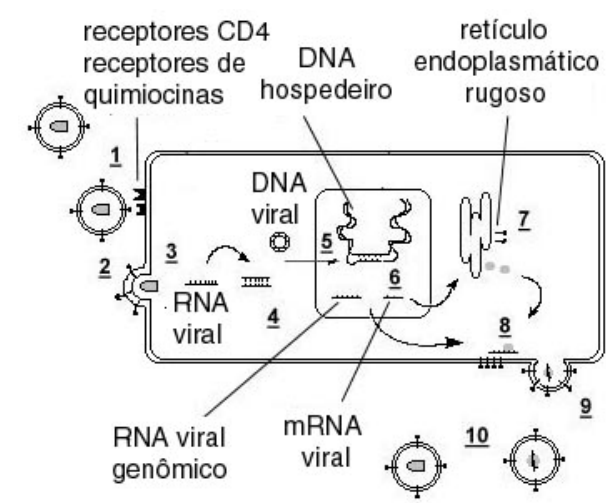

Figura 2. Ciclo de replicação do HIV. $\underline{\mathbf{1}}$ adsorção; $\underline{\mathbf{2}}$ fusão; $\underline{\mathbf{3}}$ desencapeamento; $\underline{4}$ transcrição reversa; $\underline{\mathbf{5}}$ integração ao genoma do hospedeiro; $\underline{6}$ transcrição em RNA viral genômico e mRNA; $\underline{7}$ tradução em poliproteinas env, gag e gag-pol; $\underline{8}$ montagem; $\underline{9}$ brotamento; $\underline{10}$ maturação

\section{ESTRATÉGIAS TERAPÊUTICAS PARA O TRATAMENTO DA INFECÇÃO POR HIV}

O ciclo de replicação do HIV apresenta diversos eventos exclusivamente relacionados a componentes virais, que podem ser utili- 
zados como alvos para intervenção quimioterápica ${ }^{31}$. Os compostos disponíveis atualmente como fármacos anti-HIV atuam na inibição no sítio de ligação da enzima transcriptase reversa ${ }^{32}$, na inibição alostérica da transcriptase reversa ${ }^{33}$ ou na inibição "competitiva" da protease $^{34}$. Uma eficácia clínica efetiva foi alcançada com a combinação de diferentes inibidores de transcriptase reversa e inibidores de protease. Entretanto, a euforia inicial com o avanço terapêutico foi rapidamente desfeita frente à velocidade do aparecimento de cepas resistentes a diferentes combinações dos fármacos disponíveis ${ }^{31}$. A resistência viral à terapia anti-HIV disponível torna imperativo o rápido desenvolvimento de inibidores das enzimas alvo, $\mathrm{RT}$ e PR, novos e eficientes, assim como de fármacos que atuem em outros pontos do ciclo de replicação viral.

\section{Inibidores de transcriptase reversa}

A ausência de uma enzima análoga à RT em células humanas e o conhecimento prévio de inibidores de RT, utilizados no tratamento de retroviroses animais tornaram a inibição da RT o alvo terapêutico óbvio para o tratamento da infecção por HIV ${ }^{35}$. Um destes inibidores, o AZT sintetizado inicialmente como um agente antitumor e apresentando atividade antiretroviral contra vírus de leucemia em murinos, demonstrou atividade inibitória contra HIV-1 in vitro e tornou-se o primeiro fármaco a ser aprovado para o tratamento da AIDS e condições relacionadas a ela ${ }^{33}$. Este sucesso inicial estimulou a avaliação da atividade anti-HIV de diversos análogos de nucleosídeos, descritos ou recém sintetizados, o que resultou na aprovação de cinco inibidores de RT nucleotídicos/nucleosídicos (NRTIs) ${ }^{36}$.

O domínio catalítico da transcriptase reversa, o heterodímero p66/ p51, chamado domínio "palma", apresenta dois sítios de ligação que podem ser considerados alvos para intervenção quimioterápica: o sítio de ligação do substrato, local de atuação dos inibidores de RT nucleotídicos/nucleosídicos (NRTIs) e um sítio de ligação alostérico, onde atuam os inibidores de RT não nucleosídicos (NNRTIs) ${ }^{37}$.

Os seis NRTIs disponíveis para o tratamento da infecção por HIV, zidovudina (AZT, 1), didanosina (ddI, 2), zalcitabina (ddC, 3), stavudina (d4T, 4), lamivudina (3TC, 5) e abacavir (6), atuam de forma similar a outros agentes antivirais. Estes fármacos precisam sofrer fosforilação intracelular que os converte e sua forma 5'trifosfato, a qual atua como um inibidor competitivo ou um substrato alternativo da $\mathrm{RT}^{38}$. Se o inibidor for incorporado à cadeia de DNA, torna-se impossível a continuidade do crescimento desta. Assim, os NRTIs atuam como terminadores de cadeia ${ }^{39}$.

O ponto chave para a atividade anti-HIV dos análogos de nucleosídeos é a etapa inicial de fosforilação por cisases intracelulares

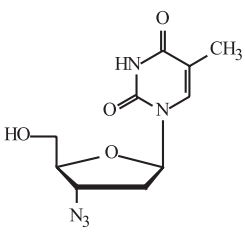

Zidovudina, AZT (1) $\mathrm{IC}_{50}=0,006 \mu \mathrm{M}$

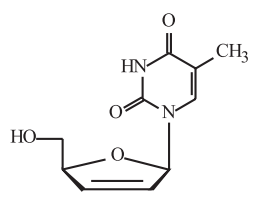

St a vudina, $\mathrm{d} 4 \mathrm{~T}(4)$ $\mathrm{IC}_{50}=0,005 \mu \mathrm{M}$

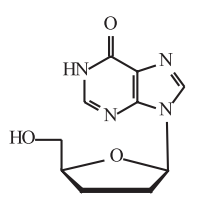

Didanosina, ddI (2) $\mathrm{IC}_{50}=10 \mu \mathrm{M}$

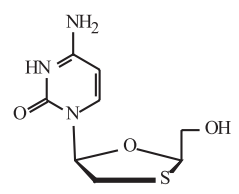

Lamivudina, 3TC (5) IC $50=0,18 \mu \mathrm{M}$

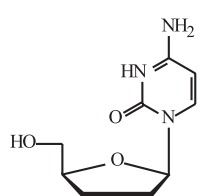

Zal cit abina, ddC (3) $\mathrm{IC}_{5}=0,046 \mu \mathrm{M}$

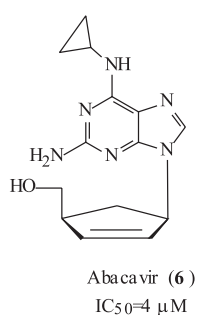

(Esquema 1). Análogos de nucleosídeos que não apresentam a capacidade se serem convertidos em nucleotídeos serão fatalmente inativos contra $\mathrm{HIV}^{31}$. Com o objetivo de contornar este problema foram desenvolvidos novos análogos acíclicos fosforilados de nucleotídeos como PMEA (7) e PMPA (8). Estes derivados necessitam apenas duas etapas de fosforilação para serem convertidos nos trifosfatos ativos que atuam como terminadores de cadeia ${ }^{40}$.

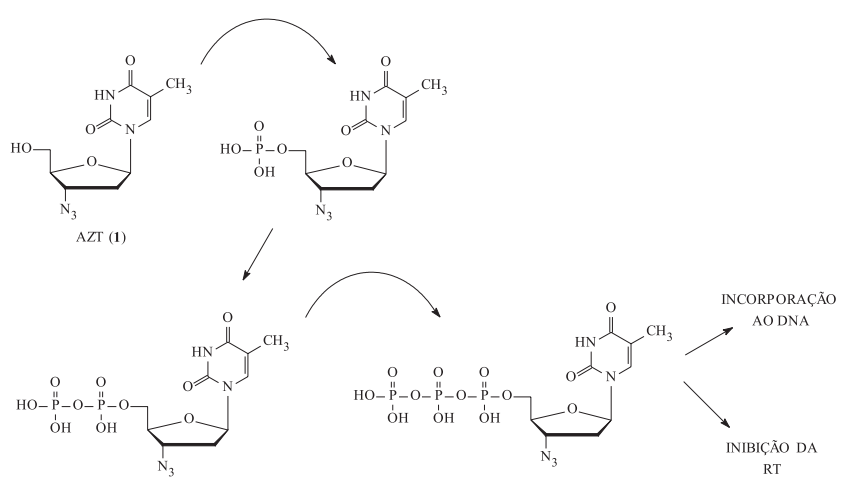

Esquema 1. Fosforilação intracelular do AZT

A avaliação farmacológica em cultura de células, modelos animais e em humanos, demonstrou a alta potência e seletividade de PMEA (7) e PMPA (8) ${ }^{41}$. A baixa biodisponibilidade por via oral destes compostos faz necessária a sua administração como prófármaco. Entre os derivados sintetizados, o bis(POM)PMPA (9) alcançou estágio avançado em ensaios clínicos (o derivado (9) foi aprovado pelo FDA para o tratamento da infecção por HIV em outubro de 2001).
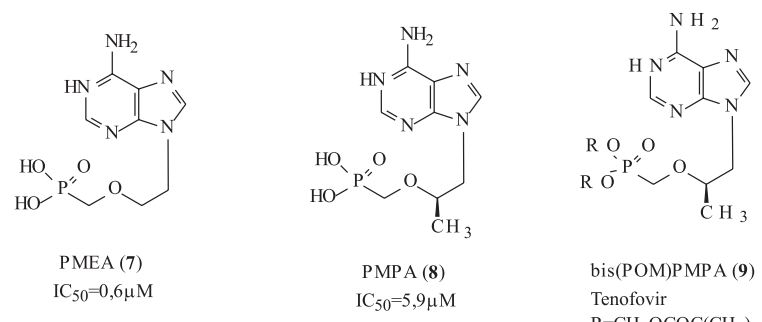

bis(POM)PMPA (9)

Tenofovir

$\mathrm{R}=\mathrm{CH}_{2} \mathrm{OCOC}\left(\mathrm{CH}_{3}\right)_{3}$

No final da década de oitenta, dois compostos, HEPT (10) e TIBO (11) foram identificados como potentes protótipos anti-HIV em programas de seleção em cultura de células infectadas ${ }^{42,43}$. Posteriormente, foi verificada a alta potência e especificidade destes compostos na inibição da RT de HIV-1 ${ }^{44,45}$. A descoberta destes novos inibidores estimulou o rastreamento de novos compostos com atividade semelhante, o que resultou na identificação de nevirapina $(\mathbf{1 2})^{46}$, piridinonas como L-697,661 (13) ${ }^{47}$, bis(heteroaril)piperazinas (BHAP) como U-90152 (delavirdina, 14) ${ }^{48}$, TSAO-m ${ }^{3} \mathrm{~T}(\mathbf{1 5})^{49}$, loviride $(\mathbf{1 6})^{50}$, além de compostos estruturalmente derivados de HEPT (10) e TIBO (11), como MKC-442 $(\mathbf{1 7})^{51}$ e tivirapina $(\mathbf{1 8})^{52}$, respectivamente.

Estes derivados foram qualificados como inibidores de transcriptase reversa não nucleosídicos (NNRTI), com base em sua capacidade de interação específica com a RT de HIV-1. Atualmente, mais de trinta classes distintas de compostos, apresentando esta atividade farmacológica, foram identificadas. Três destes compostos, nevirapina (Viramune ${ }^{\circledR}$ ) (12), delavirdina (Rescriptor ${ }^{\circledR}$ ) (14) e efavirenz (Sustiva $\left.{ }^{\circledR}\right)(\mathbf{2 0})$, foram aprovados para o tratamento da infecção por HIV ${ }^{36}$. 
<smiles>CCOCn1c(Sc2ccccc2)cc(=O)[nH]c1=O</smiles>

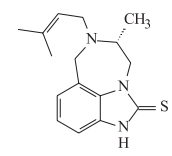

HEPT (10) $\mathrm{IC}_{50}=7 \mu \mathrm{M}$

$\mathrm{TIBO}(11)$
$\mathrm{IC}_{50}=0,9 \mu \mathrm{M}$
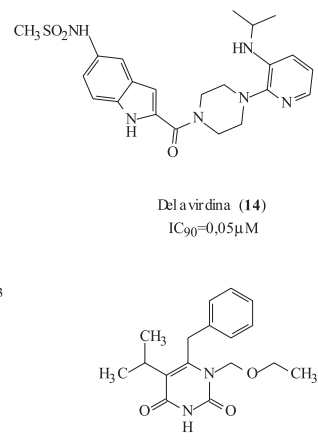

MC 442 (17) $\mathrm{IC}_{50}=0,0042 \mu \mathrm{M}$

Efavirenz DMP 266 (20) $\mathrm{IC}_{95}=0,0015 \mu \mathrm{M}$

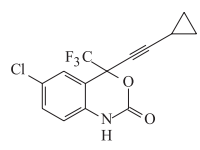

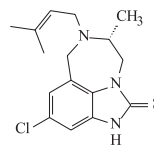

R82913 (19) $\mathrm{IC}_{50}=0,0015 \mu \mathrm{M}$
A principal vantagem dos NNRTI sobre os inibidores nucleosídicos da RT é que não necessitam de uma etapa inicial de ativação intracelular, i.e. fosforilação ${ }^{53}$. Os NNRTIs não interagem com o sítio ativo da RT, mas sim com um sítio de ligação alostérico, localizado a aproximadamente $10000 \mathrm{pm}$ de distância do sítio catalítico $^{53}$. Embora os NNRTIs sejam quimicamente diversificados, vários estudos cristalográficos têm demonstrado que estes compostos apresentam o mesmo modo de ligação à $\mathrm{RT}^{54}$. A ligação dos NNRTIs ao seu alvo leva a um reposicionamento da folha $\beta$, localizada na subunidade p66, especialmente dos resíduos de tirosina 181 e 188 além dos resíduos catalíticos de ácido aspártico, o que inativa a $\mathrm{RT}^{55}$. Estes dados sugerem que estes derivados fixam a enzima em uma conformação inativa. Segundo estudos de modelagem molecular, diversos NNRTIs como $\alpha$-APA R 89439, loviride (16), 8-cloro-TIBO, R86183 tivirapina (18), 9-cloro-TIBO R82913 (19), nevirapina (12) e delavirdina (14) mantém uma conformação bastante similar, tipo "borboleta", atuando como doadores de elétrons $\pi$ à cadeias laterais de amino ácidos aromáticos ao redor do sítio de ligação ${ }^{56}$.

Em virtude dos NNRTIs apresentarem praticamente o mesmo modo de ligação à RT, mutações que levam à resistência a fármacos desta classe, como a substituição da Tyr 181 por Cys, inviabilizam a terapia com outros NNRTIs, devido à resistência cruzada ${ }^{57}$.

\section{Inibidores de HIV protease}

Como descrito anteriormente, a HIV PR é a responsável pelo processamento das poliproteínas gag e gag-pol, levando à formação das proteínas estruturais e funcionais do vírus ${ }^{58}$. A inativação da PR, em estudos de mutagênese sítio dirigida ${ }^{59}$ ou pela utilização de inibidores de protease ${ }^{60}$, demonstrou a incapacidade das partículas virais formadas de se replicar, produzindo, após a etapa de "brotamento", apenas vírions não infectivos. Estes estudos sustenta- ram a hipótese de que inibidores específicos de HIV PR poderiam prevenir a formação de vírions infectivos a partir de linfócitos $\mathrm{T}$ infectados, o que resultaria em um efeito terapêutico anti-viral significante $^{60}$.

Entre os diversos inibidores de HIV-1 PR desenvolvidos, os compostos saquinavir (Ro 31-8959, Invirase ${ }^{\circledR}$ ) (21), indinavir (MK-639, Crixivan $\left.^{\circledR}\right)\left(\right.$ 22), ritonavir (ABT-538, Norvir $\left.{ }^{\circledR}\right)(\mathbf{2 3})$, nelfinavir (Ag1343, Viracept $\left.{ }^{\circledR}\right)(\mathbf{2 4})$, amprenavir $\left(\mathrm{VX}-478\right.$, Agenerase $\left.^{\circledR}\right)(\mathbf{2 5})$ e lopinavir (ABT-378, Kalera $\left.{ }^{\circledR}\right)$ (26) foram aprovadas em diversos países para comercialização como fármacos úteis no tratamento da AIDS $^{36}$.
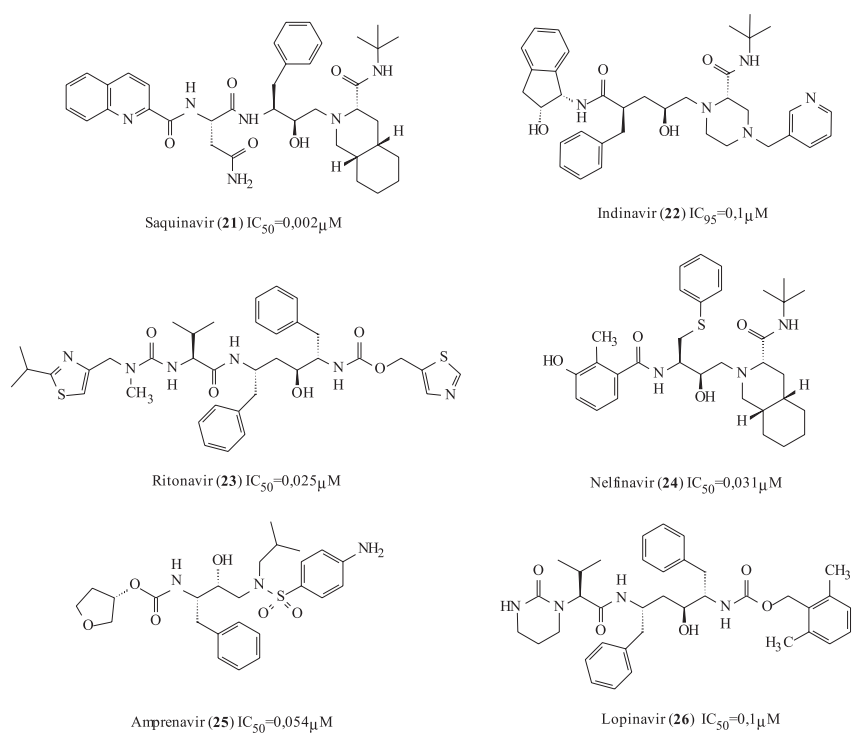

As proteases retrovirais pertencem à família das proteases aspárticas, que apresentam resíduos deste amino ácido em uma região altamente conservada do sítio catalítico ${ }^{61}$. Ao contrário de proteases aspárticas "não virais", estruturas apresentando geralmente mais de 300 amino ácidos ${ }^{30}$, as proteases aspárticas retrovirais possuem menos do que 130 resíduos de amino ácido, e apresentam pouca homologia com as proteases não virais ou mesmo com outras proteases virais ${ }^{30}$. A expressão do gene pol do HIV em Escherichia coli demonstrou a atividade autocatalítica da porção da protease inserida na poliproteína gerada, levando à liberação de um peptídeo de 99 amino ácidos, que foi posteriormente purificado, permitindo a sua caracterização bioquímica ${ }^{62}$. Estudos de modelagem molecular sugeriram que a protease de HIV poderia formar estruturas com tamanho equivalente ao das proteases não virais, através da dimerização de suas subunidades de 99 amino ácidos, e que cada monômero forneceria uma tríade catalítica Asp-Thr-Gly para o sítio ativo, localizado na interface entre as subunidades ${ }^{63}$. Estes resultados foram posteriormente confirmados por estudos cristalográficos da enzima, que demonstraram que a HIV PR se apresenta como um homodímero contendo, em sua forma não ligada, um eixo de simetria $C_{2}{ }^{64}$, que é perturbado quando a enzima se liga a um substrato ou um inibidor assimétrico ${ }^{65}$. As regiões amino e carboxi terminal dos monômeros são as responsáveis pela estabilização da estrutura dimérica da HIV PR. Estas regiões apresentam-se na forma de folhas $\beta$, que se entrelaçam de forma antiparalela ${ }^{30}$. A HIV PR apresenta duas "abas" que podem se movimentar cerca de 700pm, em relação à posição inicial, permitindo a entrada do substrato e ligando-se a este, contribuindo assim para a interação enzima-substrato ${ }^{65}$.

O desenvolvimento racional de inibidores de HIV PR teve início 


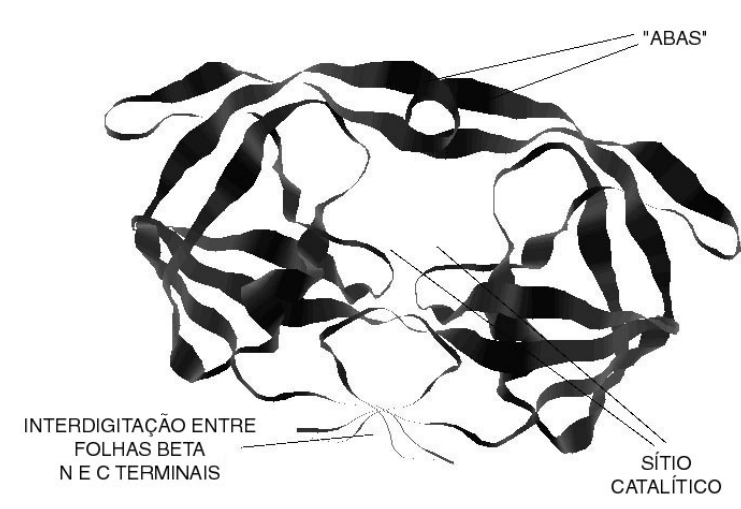

Figura 3. HIV-protease

com o estudo da especificidade da enzima pelo substrato ${ }^{66}$ e proposição do seu mecanismo de ação ${ }^{67}$. A substituição de uma ligação amídica de um substrato conhecido por uma ligação não hidrolizável poderia, a priori, levar à obtenção de inibidores eficazes ${ }^{60}$. O processamento dos substratos naturais da HIV PR, as poliproteínas gag e gag-pol, envolve a clivagem em apenas oito pontos, sugerindo uma alta especificidade da PR quanto à sequiência primária de seus substratos $^{30}$. Três pontos de clivagem nos substratos naturais envolvem o reconhecimento da sequiência Ser(The)-Xaa-Yaa-Phe(Tyr)*Pro (* indica o ponto de clivagem). Outros pontos de clivagem são menos específicos conservando, entretanto, resíduos hidrofóbicos nas posições P1 e P1'. Estudos sistemáticos sobre os requisitos estruturais para os resíduos P1, P2, P3, e P2' foram realizados ${ }^{30,60}$. Destes dados, concluiu-se que um modelo adequado para o desenvolvimento de um inibidor deveria apresentar um resíduo pequeno e hidrofílico em P4, grupamentos grandes de polaridade variável em P3 e P3', Asn ou resíduos hidrofóbicos em $\mathrm{P} 2$, resíduos hidrofóbicos ou aniônicos em P2' e grupamentos hidrofóbicos em P1 e P1'. Adicionalmente, estes estudos indicaram que o sítio catalítico pode acomodar até um heptapeptídio, o que compreende os resíduos P4 a P3 ${ }^{30}$.

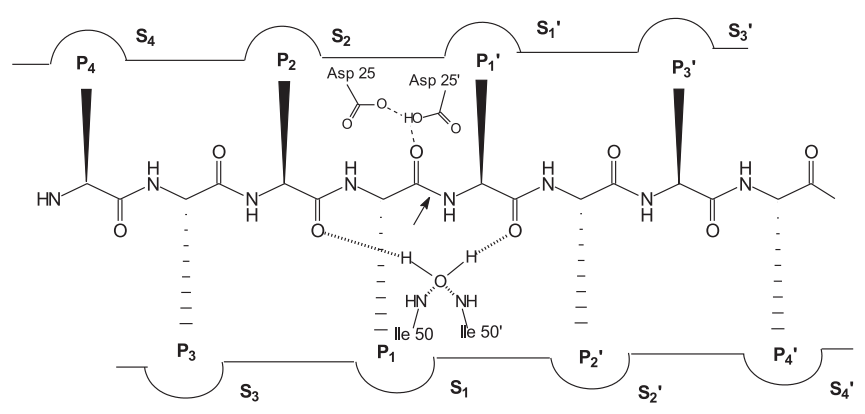

Figura 4. Diagrama das interações hidrofóbicas e ligações de hidrogênio entre a enzima e o substrato

O mecanismo provável da hidrólise promovida pela HIV PR, segundo dados de efeito isotópico e estudos cinéticos com a variação de $\mathrm{pH}^{67}$, indica que tanto Asp-25 como Asp-25' estão envolvidos, um resíduo na forma protonada e o outro na forma iônica, como representado no Esquema 2. A hidratação da amida levaria à formação de um intermediário tetraédrico, provavelmente com grande afinidade pelo sítio catalítico, que poderia ser utilizado como modelo para o desenvolvimento de inibidores que mimetizem o estado de transição da hidrólise ${ }^{68}$.
Tabela 1. Resíduos de amino ácidos adequados e não adequados à interação com a enzima nas posições P3, P2, P1 e P2'.

\begin{tabular}{lll}
\hline & Adequado & Não adequado \\
\hline P3 & $\begin{array}{l}\text { Gln, Cys, Tyr, Arg, Val, } \\
\text { Asn, Asp, Glu }\end{array}$ & Pro \\
P2 & $\begin{array}{l}\text { Val, Ile, Leu, Phe, ala, } \\
\text { Asp, Asn }\end{array}$ & Pro, Gly \\
P1 & $\begin{array}{l}\text { Tyr, Phe, Met, Leu, } \\
\text { norleucina }\end{array}$ & Glu, Arg, Ile, Val \\
P2' & Ile, Ala, Leu, & Trp, Phe, Gly \\
\hline
\end{tabular}

HO
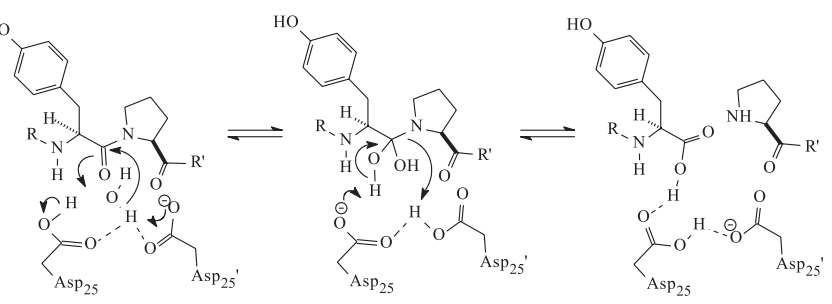

Esquema 2. Mecanismo de hidrólise da HIV PR

O primeiro protótipo de inibidor de HIV protease foi o produto de fermentação microbiológica pepstatina ${ }^{69}$, um inibidor conhecido de proteases aspárticas como a pepsina. Embora a pepstatina não tenha se mostrado um inibidor potente da HIV PR $\left(\mathrm{K}_{\mathrm{i}}=1 \mu \mathrm{M}\right)$, seu análogo acetilado, a acetilpepstatina (27), apresentou um $\mathrm{K}_{\mathrm{i}}$ da ordem de $35 \mathrm{nM}^{70}$. A subunidade hidroxietileno do amino ácido não usual statina, presente no derivado (27), pode ser considerado um isóstero adequado para a ligação amídica e foi utilizado como base para o desenvolvimento de inibidores que mimetizavam o estado de transição tetraédrico da hidrólise ${ }^{30}$.

Diversos inibidores de HIV protease foram desenvolvidos posteriormente utilizando grupamentos como hidroxietileno, diidroxietileno ou difluorocetonas, entre outros, como isósteros de amida $^{30,68,71,72}$. O isóstero não hidrolizável de amida mais simples, a amida reduzida (alquil amina), não demonstrou ser um grupamento adequado para inibidores de $\mathrm{HIV} \mathrm{PR}^{34}$. Como para outras proteases aspárticas, a configuração absoluta das hidroxilas é fundamental para a atividade inibitória da HIV PR. Inibidores apresentando o álcool secundário com configuração $S$ apresentaram potência farmacológica mais elevada que seu isômero $R^{68}$.

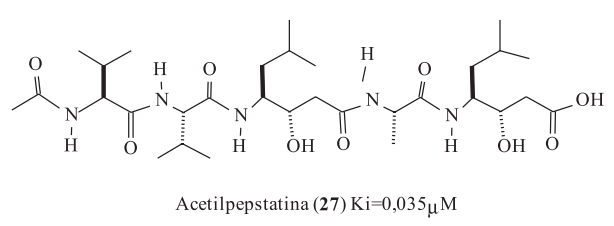

O desenvolvimento do saquinavir (21) pelo grupo Hoffmann-La Roche $^{34}$, o primeiro inibidor de HIV PR aprovado, baseou-se na utilização do grupamento hidroxietileno e na especificidade da HIV PR por ligações Phe-Pro e Tyr-Pro. Estudos enzimáticos permitiram concluir que a configuração $R$ inesperada para o grupamento hidroxietileno era a mais adequada para a atividade biológica, assim como o comprimento mínimo do isóstero era de três resíduos de amino ácidos em direção ao N-terminal e dois amino ácidos em direção ao C-terminal. O aumento mais significativo na potência 
farmacológica foi alcançado pela substituição da prolina por (S,S,S)decaidroisoquinolina-3-carbonil (DIQ). O composto resultante, Ro 31-8959 (21) mostrou uma alta seletividade, inibindo menos de $50 \%$ das proteases aspárticas humanas. O composto foi posteriormente submetido a testes clínicos e aprovado pelo FDA em 1995.
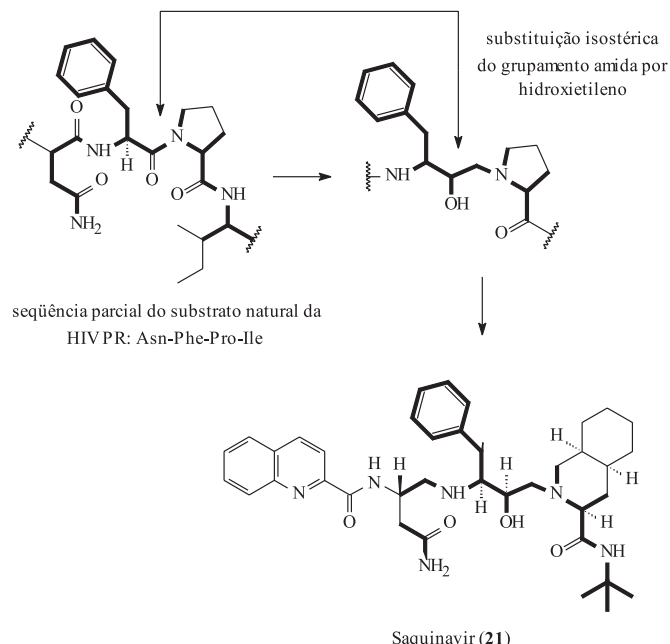

Esquema 3. Desenvolvimento do saquinavir (21) a partir da seqüência da poliproteína gag-pol. O esqueleto em comum entre as estruturas é representado em negrito

O grupo de pesquisas da Abbott desenvolveu o ritonavir (23) baseado na premissa de que compostos contendo um eixo de simetria $C_{2}$ apresentariam uma complementaridade estrutural adequada com a enzima que contém da mesma forma um eixo de simetria $C_{2}$, levando assim a uma potência farmacológica adequada ${ }^{73}$. Compostos com eixo de simetria $C_{2}$, por mostrarem uma menor relação estrutural com peptídeos, apresentariam ainda uma melhor estabilidade metabólica in vivo e uma menor afinidade com enzimas huma$\operatorname{nas}^{34}$. Assim, foram sintetizados o hidroxietileno A-74704 (28) e o diidroxietileno (29), que embora fossem inibidores potentes em culturas de célula, não apresentaram resultados satisfatórios in vivo quanto à seletividade enzimática frente a outras proteases aspárticas e biodisponibilidade ${ }^{34}$. Posteriormente, Dreyer e colaboradores ${ }^{74}$ demonstraram, através de estudos cristalográficos, que inibidores simétricos ligavam-se à HIV PR de forma assimétrica, o que desviou o programa de pesquisas do conceito original dando origem ao deriva- do assimétrico A-80987 (30) e, posteriormente, ABT-538 (ritonavir) $(\mathbf{2 3})^{75}$ aprovado pelo FDA em 1996.

Três outros inibidores de protease foram aprovados para o tratamento da infecção por HIV ${ }^{34}$ : indinavir (22) desenvolvido pela Merck e aprovado em 1996, nelfinavir (24) da Augouron, o primeiro inibidor de HIV PR aprovado para uso pediátrico em 1997, o amprenavir (25) desenvolvido pela Glaxo e aprovado pelo FDA em 1999 e, mais recentemente, o lopinavir (26) da Abbott aprovado em 2000.

A análise por difratometria de raios-X dos complexos entre os diversos inibidores descritos e a HIV-1 PR demonstraram que estes compostos apresentam como característica comum a presença de uma molécula de água na rede cristalina, formando ligações de hidrogênio com a enzima e o inibidor ${ }^{76}$. Nos cristais estudados, esta molécula de água promove o contato entre os átomos de oxigênio carbonílicos na porção P2/P1' dos inibidores e os grupamentos amida de Ile50/ ile50' da "aba" presente na enzima ${ }^{77}$ (Figura 4).

Estes estudos inspiraram a concepção de inibidores contendo grupamentos capazes de mimetizar as interações da molécula de água com a enzima ${ }^{78}$, como os derivados DMP-323 (31) e DMP-450 (32 $)^{79}$. Nestes compostos, pertencentes à classe das uréias cíclicas, o resíduo diidroxietileno, contido nos anéis de sete membros, pode interagir via ligações de hidrogênio com os amino ácidos da enzima ${ }^{78}$.

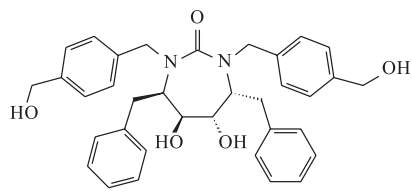

DMP-323(31) $\mathrm{IC}_{50}=0,057 \mu \mathrm{M}$

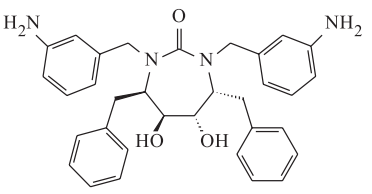

DMP-450 (32) $\mathrm{IC}_{50}=0,130_{\mu} \mathrm{M}$

\section{Inibidores da integrase}

A integração do DNA viral no cromossomo hospedeiro consiste em um processo essencial no ciclo de reprodução do HIV ${ }^{80}$. A HIV-1 integrase (IN) é uma enzima de $32 \mathrm{kDa}$ que promove a integração do DNA viral em um processo de duas etapas. A primeira etapa, chamada de processamento 3', consiste na remoção de dois nucleotídeos das terminações 3' do DNA viral. No passo seguinte, chamado de transferência de fita de DNA, duas transesterificações integram as terminações do DNA viral no cromossomo hospedeiro ${ }^{81}$. A integrase (IN) contém três domínios, o domínio N-terminal (resíduos de amino ácidos 1-50), onde se encontram dois resíduos de histidina e dois de cisteína que promovem a ligação com Zn(II). O domínio "cerne" (re-
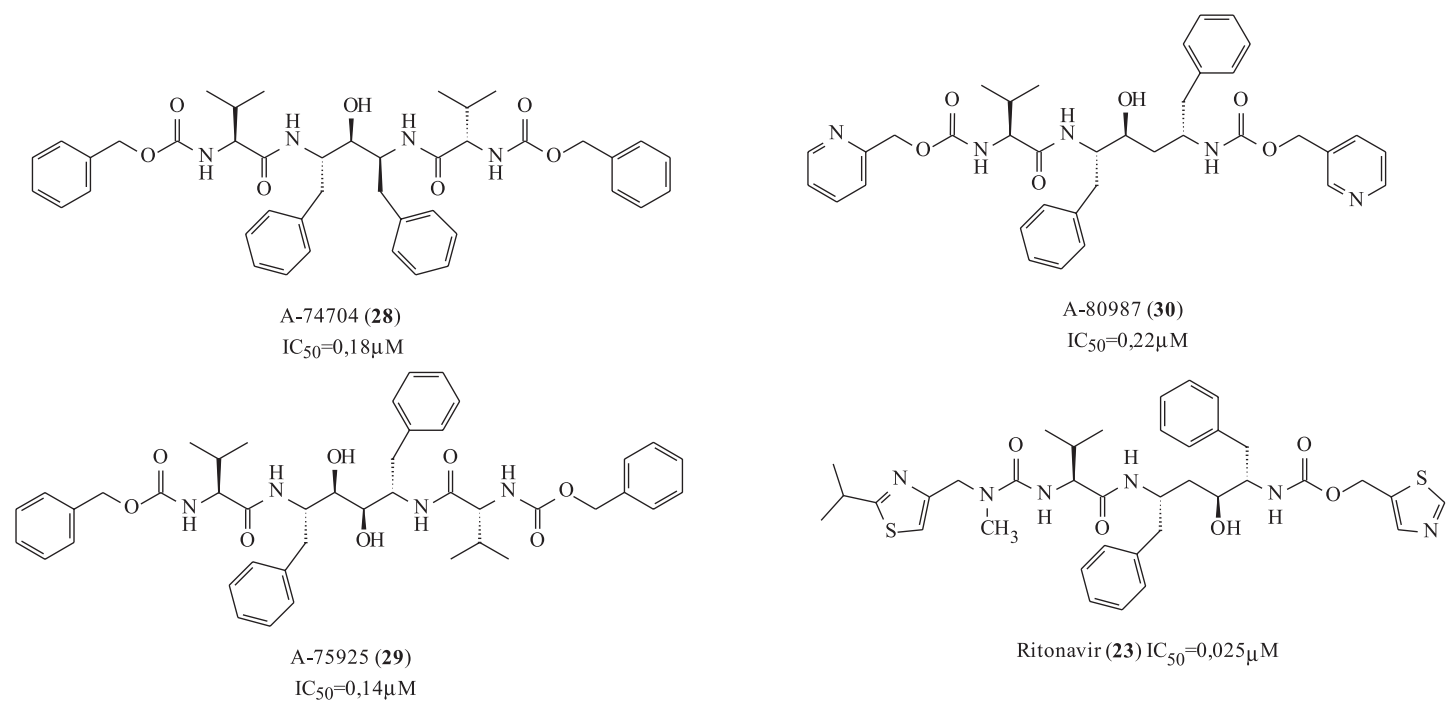

Ritonavir (23) $\mathrm{IC}_{50}=0,025 \mu \mathrm{M}$ 
síduos de amino ácidos 50-212) contendo os sítios catalíticos para a endonuclease e polinucleotidil transferase, a tríade ácida Asp 64, Asp 116 e Glu52, onde se ligam $\mathrm{Mn}$ (II) ou $\mathrm{Mg}$ (II), chamada de "motriz DDE”. O domínio C-terminal (amino ácidos 213-288) contém resíduos de amino ácidos básicos e liga-se ao DNA ${ }^{3}$.

A estrutura de cada um dos domínios da IN foi obtida com alta resolução por RMN (domínios N- e C-terminais) e cristalografia de raios-X (domínio cerne) ${ }^{82}$. Embora cada um destes domínios forme separadamente uma estrutura dimérica, é provável que a enzima completa seja ativa na forma de um tetrâmero ou mesmo um octâmero ${ }^{83}$.

Testes rápidos e sensíveis estão disponíveis para a avaliação da atividade inibitória sobre a HIV-IN. A enzima pode ser obtida em quantidade suficiente a partir de tecnologia de DNA recombinante ${ }^{84}$.

Embora vários compostos, estruturalmente diversificados, apresentem atividade inibitória sobre a enzima isolada, apenas poucos apresentam-se ativos contra o HIV em testes em cultura de células ${ }^{85}$. Entre esta coleção restrita, apenas os derivados dicetoácidos como 5CITEP ${ }^{86}(36)$ e L-731-988 (37 ${ }^{87}$ tiveram sua ação antiviral atribuída especificamente à inibição da integrase. Aparentemente, estes compostos têm a capacidade de prevenir o processo de integração mesmo após a formação do chamado complexo pré-integrativo, formado pelo DNA viral, integrase e outras proteínas virais. Os compostos inativos em cultura de células inibem a integrase apenas antes da formação deste complexo nucleoproteico ${ }^{87}$.

Entre os compostos com atividade inibitória da integrase descrita, alguns tiveram seu sítio de ligação estabelecido como o derivado nucleotídico AZT monofosfato (AZTMP, 33), que se liga à três resíduos de lisina (K156,159 e 160) presentes no cerne da enzima e responsáveis pela ligação com $\mathrm{DNA}^{88}$. Compostos dinucleotídicos
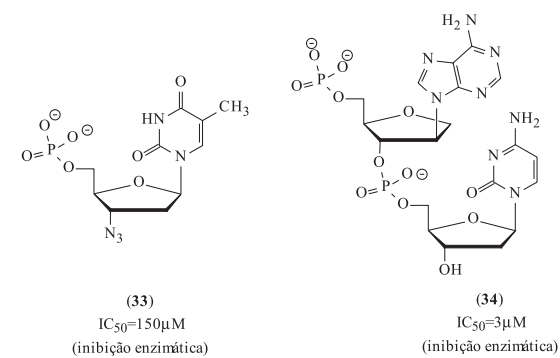

(inibição<smiles>O=C(O)C(=O)CC(=O)c1cccn1Cc1ccc(F)cc1</smiles>

$\stackrel{(36)}{\mathrm{IC}_{50}=1 \mu \mathrm{M}}$

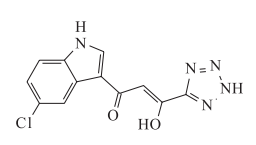

(37)

$\mathrm{IC}_{50}=2,3 \mu \mathrm{M}$

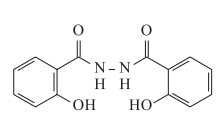

$(\mathbf{3 8})$
$\mathrm{IC}_{50}=0,73 \mu$ $\mathrm{IC}_{50}=0,73 \mu \mathrm{M}$

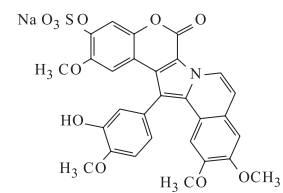

(39)
$\mathrm{IC}_{50}=62 \mu \mathrm{M}$

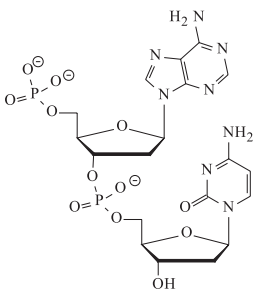

(35)

$$
\mathrm{IC}_{50}=25 \mu \mathrm{M}
$$
$\mathrm{IC}_{50}=25 \mu \mathrm{M}$
(inibição enzimática) (inibição enzimática)

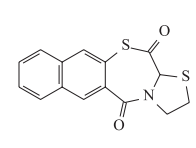

$(\mathbf{4 0})$
$\mathrm{IC}_{50}=60 \mu \mathrm{M}$

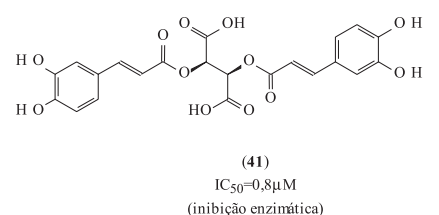

como pdApdC (34) e isodinucleotídicos como pisoApdC (35) são capazes de se ligarem à este mesmo sítio, deslocando o DNA ${ }^{89}$.

Estudos cristalográficos demonstraram a ligação do derivado 5CITEP (35) em um sítio diferente dos derivados nucleotídicos, o que acarreta no deslocamento do "motriz DDE" e do sítio de ligação com o DNA, com conseqüente inibição da enzima ${ }^{86}$. A quelação com metais divalentes $\mathrm{Mg}(\mathrm{II})$ e $\mathrm{Mn}$ (II) no sítio catalítico da integrase é o provável modo de ligação dos derivados aromáticos hidroxilados como a diidrazida (38), o lamelarina $\alpha$ 2-sulfato (39) e o derivado $(\mathbf{4 1})^{82,90}$.

\section{Inibidores da adsorção viral}

O primeiro composto a ter propriedades anti-AIDS reconhecida foi a suramina ${ }^{91}(\mathbf{4 2})$. Posteriormente, foi verificado que seu mecanismo de ação era exercido através da prevenção da ligação entre o vírus e a célula ${ }^{92}$. O efeito da suramina, um hexasulfonato, na adsorção viral pode ser atribuído à sua característica polianiônica. A suramina foi também o primeiro composto a ser testado clinicamente, demonstrando uma redução expressiva nos níveis plasmáticos de vírus após injeção i.v. ${ }^{37}$. Entretanto, após descontinuidade da terapia a carga viral aumenta rapidamente. Os testes clínicos com a suramina foram abandonados em virtude de sua alta toxidade. Adicionalmente, diversos compostos polianiônicos demonstraram capacidade de bloquear a adsorção viral ${ }^{93,94}$. Entre eles estão o dextran sulfato (43) e poli-naftaleno sulfonato (44). O último composto, conhecido como PRO 2000, encontra-se em testes clínicos para terapia anti-HIV.

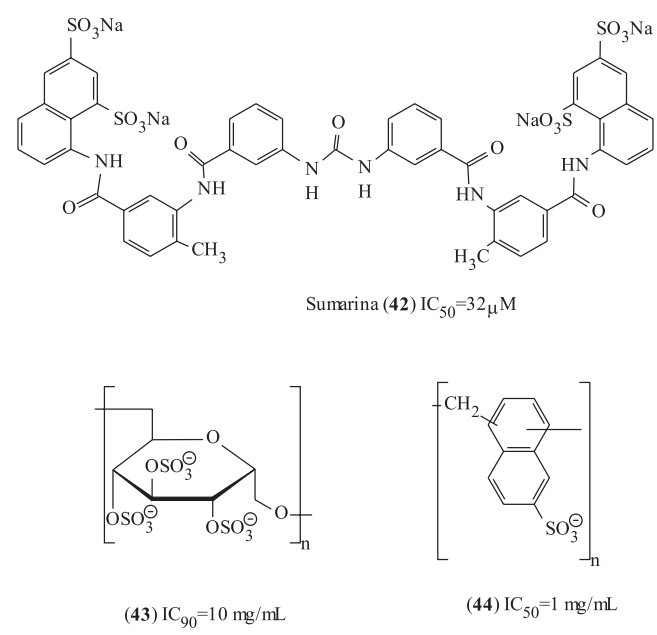

Inibidores da fusão vírus-célula

O processo de fusão vírus-célula, mediado pela proteína TM (gp41), pode ser inibido por albuminas negativamente carregadas ${ }^{95}$ como Suc-HSA (albumina sérica humana succinilada) e Aco-HSA (albumina sérica humana aconitilada), além de derivados do ácido betulínico como RPR $103611^{96}$ (45) e pentafuside T2097, um peptídio correspondente a uma região de 36 amino ácidos da TM.

Outros inibidores típicos de fusão são as biciclamas como JM $3100^{98}$ (46). Estes derivados apresentam dois grupamentos ciclama unidos por uma ponte aromática ou alifática. O derivado JM 3100 (46) inibe a replicação celular em concentrações nanomolares, através de ligação específica com os coreceptores CXCR4 ${ }^{99}$.

\section{Inibidores do descapeamento viral}

Compostos da classe das 2,2'-ditiobisbenzamidas (DIBAs) ${ }^{100}$ como (47) e (48) apresentam a capacidade de ligação com a proteína 
<smiles>CC(C)CC(NC(=O)CCCCCCCCNC(=O)C12CCC(C(C)C)C1CCC1C3(C)CCC4C(C)(C)C(O)CCC4(C)C3CCC12C)C(O)CC(=O)O</smiles>

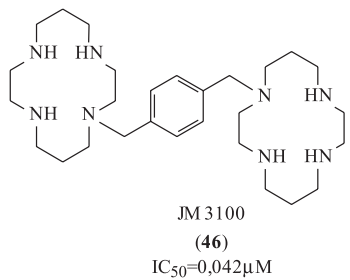

$\mathrm{NC}(\mathrm{p} 7)^{100}$, interferindo assim tanto na fase de desencapeamento quanto na montagem do vírus, etapas do ciclo de replicação viral onde a proteína $\mathrm{p} 7$ tem papel relevante.
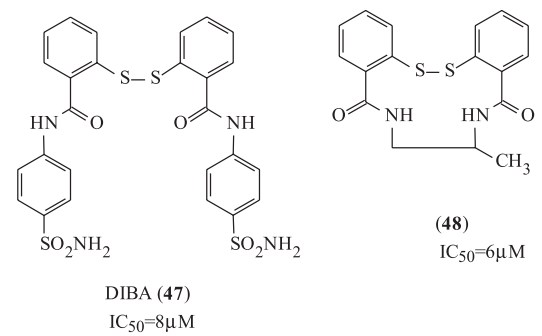

(48) $\mathrm{IC}_{50}=6 \mu \mathrm{M}$ $\mathrm{IC}_{50}=8 \mu \mathrm{M}$

\section{Inibidores da transcrição do DNA pró-viral}

Entre os compostos capazes de interferir com o processo de transativação da Tat estão a benzodiazepina Ro 5-3335 (49) e seu precursor sintético, o derivado $(\mathbf{5 0})^{101}$. Estes compostos, chamados de antagonistas de Tat, não interferem diretamente na proteína viral Tat, mas em outros fatores celulares que estão envolvidos no processo de transativação ${ }^{37}$.

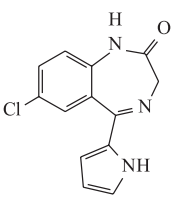

Ro 5-3335 (49) $\mathrm{IC}_{50}=1 \mu \mathrm{M}$

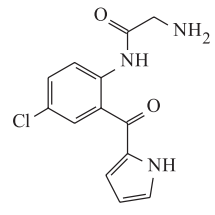

(50)

$\mathrm{IC}_{50}=0,62 \mu \mathrm{M}$

\section{Inibidores da tradução de mRNA viral}

Oligonucleotídeos que se hibridizam especificamente com sequiências definidas de mRNA viral podem interferir no processo de síntese de proteínas virais. GEM91, um 25-mer oligodeoxinucleotídeo, complementar ao sítio de iniciação de tradução do mRNA viral $^{37}$, é um exemplo de estrutura capaz de inibir a tradução. O maior problema relacionado com a utilização deste tipo de composto é sua baixa capacidade de penetração celular.

\section{CONCLUSÕES}

Diversas etapas do ciclo replicativo do HIV foram identificadas como alvos para intervenção farmacológica. Assim, vários compostos são candidatos a fármacos terapeuticamente úteis, uma vez que inibem as etapas do ciclo de replicação viral. Entretanto, apenas inibidores de trascriptase reversa e protease estão disponíveis como fármacos para a terapia anti-HIV. A terapia combinada de NRTIs, NNRTIs e inibidores de protease, o notório "coquetel" anti-AIDS, permite manter níveis extremamente baixos ou mesmo indetectáveis de partículas virais circulantes, o que está diretamente relacionado com o desenvolvimento da AIDS ${ }^{102}$. Apesar deste avanço terapêutico efetivo, que permitiu o aumento da expectativa de vida de pacientes soropositivos, a cura da AIDS ainda não foi alcançada, uma vez que vírus residentes em linfócitos T de "memória" não são erradicados através da terapia disponível. Estes vírus latentes se replicam continuamente, quando na descontinuidade da terapia ou no surgimento de mutações que confiram a estes resistência aos fármacos utilizados. Assim, o desenvolvimento contínuo de fármacos ativos contra cepas de HIV resistentes aos quimioterápicos disponíveis bem como a obtenção de agentes anti-HIV que atuem por outros mecanismos de ação se faz necessário e urgente.

\section{AGRADECIMENTOS}

\author{
À FAPERJ, FUJB - UFRJ, FINEP, CNPq, CAPES, FIOCRUZ \\ (PAPES).
}

\section{REFERÊNCIAS}

1. Gallo, R. C.; Montagneir, L.; Scient. Am. 1988, 259, 41.

2. Fauci, A. S.; Clin. Res. 1987, 35, 503.

3. Frankel, A. D.; Young, J. A. T.; Annu. Rev. Biochem. 1998, 67, 1.

4. Vaishnav, Y. N. ; Wong-Staal, F.; Annu. Rev. Biochem. 1991, 60, 577.

5. Deen, K. C.; McDougal, J. S.; Inacker, R.; Fulena-Wasserman, G.; Arthos, J.; Nature 1988, 331, 82.

6. Kowalski, M.; Potz, J.; Basiripour, L.; Dorfman, T.; Wei, C. G.; Science 1987, 237, 1351

7. Laski, L. A.; Nakamura, G.; Smith, D.; Fennie, C.; Shimasaki, C.; Cell 1987, 50, 975.

8. Clapham, P. R.; Weiss, R.A.; Nature 1997, 382, 833.

9. Clapham, P. R.; Trends Cell Biol. 1997, 7, 264.

10. Chan, D. C.; Kim, P. S.; Cell 1998, 93, 681.

11. Berger, E. A.; AIDS (supl. A) 1997, 11, 3.

12. Choe, H.; Arch. Pharmacal. Res. 1998, 21, 634.

13. Cocchi, F.; DeVico, A. L.; Garzino-Demo, A.; Cara, A.; Gallo, R. C.; Lusso, P.; Nat. Med. 1996, 2, 1244.

14. Shibo, J.; Lin, K.; Zhang, L.; Debnath, A. K.; J. Virol. Methods 1999, 80, 85.

15. Lu, M.; Kim, P. S.; J. Biochem. Struct. Dynamic 1997, 15, 465.

16. Chan, D. C.; Fass, D.; Berger, J. M.; Kim, P. S.; Cell 1997, 89, 263.

17. Cohen, E. A.; Subbramanian, R. A.; Gottlinger, H. G.; Curr. Top. Microbiol. Immunol. 1996, 214, 219.

18. Katz, R. A.; Skalka, A. M.; Annu. Rev. Biochem. 1994, 63, 7178.

19. Jones, K. A.; Peterlin, B. M.; Annu. Rev. Biochem. 1994, 63, 717.

20. Puglisi, J. D.; Tan, R. Y.; Calna, B. J.; Frankel, A. D.; Science 1992, 257, 76.

21. Aboul-ela, F.; Karn, J.; Varani, J.; J. Mol. Biol. 1995, 253, 313.

22. Hope, T. J.; Chem. Biol. 1997, 4, 335.

23. Lanb, R. A.; Pinto, L. H.; Virology 1997, 229, 1.

24. Kerkau, T.; Bacik, I.; Bennick, J. R.; Yewdell, J. W.; Hunig, T.; J. Exp. Med. 1997, 185, 1295.

25. Veronese, F. D.; Copeland, T. D.; Oroszlan, S.; Gallo, R. C.; J. Virol. Methods 1988, 62, 795.

26. Clever, J. L.; Parslow, T. G.; J. Virol. Methods 1997, 71, 3407.

27. Gonda, M. A.; Wong-Staal, F.; Gallo, R. C.; Clements, J. E.; Narayan, O.; Gilden, R. V.; Science 1985, 227, 173.

28. Kaplan, A. H.; Manchester, M.; Swanstrom, R.; J. Virol. Methods 1994, $68,6782$.

29. Zybarth, G.; Carter, C.; J. Virol. Methods 1995, 68, 3878. 
30. Meek, T. D.; J. Enzyme Inhib. 1992, 6, 65.

31. De Clercq, E.; Pure Appl. Chem. 1998, 70, 567.

32. Hyryn, D. M.; Okabe, M.; Chem. Rev. 1992, 92, 1745.

33. Tantillo, C.; Ding, J.; Jacobo-Molina, A.; Nanni, R. G.; Boyer, P. L.; Hughes, S. H.; Pawels, R.; Andries, K.; Janssen, P. A. J.; Arnold, E. J.; J. Mol. Biol. 1994, 243, 369.

34. Wlodawer, A.; Vondrasek, J.; Annu. Rev. Biophys. Biomol. Struct. 1998, 27, 249.

35. Shimada, M.; Hosaka, H.; Takaku, H.; Smith, J. S.; Roth, M. J.; Inouye, S.; Inouye, M.; J. Biol. Chem. 1994, 269, 3925.

36. http://www.fda.gov/oashi/aids/virals.html, acessada em Novembro 2001.

37. De Clercq, E.; Collect. Czech. Chem. Commun. 1998, 93, 449.

38. De Clercq, E.; Clin. Microbiol. Rev. 1995, 8, 200.

39. De Clercq, E.; J. Med. Chem. 1995, 38, 2491

40. De Clercq, E.; Biochem. Pharmacol. 1991, 42, 963.

41. Naesens, L.; Snoeck, R.; Andrei, G.; Balzarini, J.; Neyts, J.; De Clerrcq, E.; Antiviral Chem. Chemother 1997, 8, 1.

42. Pawels, R.; Andries, K.; Desmyter, J.; Schols, D.; Kukla, M. J.; Breslin, H. J.; Raeymaeckers, A.; Van Gelder, J.; Woestenborgs, R.; Heykants, J.; Schellekens, K.; Janssen, M. A. C.; De Clercq, E.; Janssen, P. A. J.; Nature 1990, 343, 470 .

43. Baba, M.; Tanaka, H.; De Clercq, E.; Pauwels, R.; Balzarini, J.; Schols, D.; Nakashima, H.; Perno, C-F.; Walker, R. T.; Miyasaka, T.; Biochem. Biophys. Res. Commun. 1989, 165, 1375.

44. Baba, M.; De Clercq, E.; Tanaka, H.; Ubasawa, M.; Takashima, H.; Sekiya, K.; Niita, I.; Umezu, K.; Nakashima, H.; Mori, S.; Shigeta, S.; Walker, R. T.; Miyasaka, T.; Proc. Natl. Acad. Sci. U.S.A. 1991, 88, 2356.

45. Baba, M.; De Clercq, E.; Tanaka, H.; Ubasawa, M.; Takashima, H.; Sekiya, K.; Niita, I.; Umezu, K.; Nakashima, H.; Mori, S.; Ito, M.; Shigeta, S.; Miyasaka, T.; Mol. Pharmacol. 1991, 39, 805.

46. Koup, R. A.; Merluzzi, V. J.; Hargarve, K. D.; Adams, J.; Grzinger, K.; Eckner, R. J.; Sullivan, J. L.; Infect. Dis. 1991, 163, 966.

47. Goldman, M. E.; Nunberg, J. H.; Schleif, W. A.; Quintero, J. C.; Siegll, P. K. S.; Hoffman, J. M.; Smith, A. M.; Emini, E. A.; Antimicrob. Agents Chemother. 1992, 36, 1019.

48. Romero, D. L.; Morge, R. A.; Genin, M. J.; Biles, C.; Busso, M.; Resnick, L.; Althaus, I. W.; Reusser, F.; Thomas, R. C.; Tarpley, W. G.; J. Med. Chem. 1993, 36, 1505 .

49. Balzarini, J.; Pérez-Pérez, M. J.; San-Felix, A.; Schols, D.; Perno, C. F.; Vandamme, A. M.; Camarasa, M. J.; De Clercq, E.; Proc. Natl. Acad. Sci. U.S.A. 1992, 89, 1073

50. Pauwels, R.; Andries, K.; Debyse, Z.; Van Daele, P.; Schols, D.; Stoffels, P.; De Vreese, K.; Woestenborgs, R.; Vandamme, A. M.; Janssen, M. A. C.; De Clercq, E.; Janssen, P. A. J.; Proc. Natl. Acad. Sci. U.S.A. 1993, 90, 1711.

51. Baba, M.; Shigeta, S.; Yuasa, S.; Takashima, H.; Sekiya, K.; Ubasawa, M.; Tanaka, H.; Miyasaka, T.; Walker, R. T.; De Clercq, E.; Antimicrob. Agents Chemother. 1994, 38, 688 .

52. Pauwels, R.; Andries, K.; Debyser, Z.; Kukla, M.-J.; Schols, D.; Breslin, H. J.; Woestenborgs, R; Desmyter, J.; Janssen, M. A. C.; De Clercq, E.; Janssen, P. A. J.; Antimicrob. Agents Chemother. 1994, 38, 2863.

53. De Clercq, E.; Antiviral Res. 1998, 38, 153.

54. Ren, J.; Esnouf, R.; Garman, E.; Somers, D.; Ross, C.; Kirby, I.; Keeling, J.; Darby, G.; Jones, Y.; Stuart, D.; Stammers, D.; Struct. Biol. 1995, 2, 193.

55. Esnouf, R.; Ren, J.; Ross, C.; Jones, Y.; Stammers, D.; Stuart, D.; Struct. Biol. 1995, 2, 303 .

56. Ren, J.; Esnouf, R.; Hopkins, A.; Ross, C.; Jones, Y.; Stuart, D.; Stammers, D.; Structures 1995, 3, 915.

57. Erickson, J. W.; Burt, S. K.; Annu. Rev. Pharmacol. Toxicol. 1996, $36,545$.

58. Freed, E. O.; Virology 1998, 251, 1.

59. Roberts, M. M.; Oroszlan, S.; Biochem. Biophys. Res. Commun. 1989, 160, 486.

60. Meek, T. D.; Lambert, D. M.; Metcalf, B. W.; Petteway, S. R; Dreyer, G. B. Em Design of anti-AIDS drugs; De Clercq, E., ed.; Elsevier: Amsterdam, 1990, p. 225.

61. Babine, R. E.; Bender, S. L.; Chem Rev. 1997, 97, 1359.

62. Darke, P. L.; Leu, C. T.; Davis, L. J.; Heimbach, J. C.; Diehl, E. E.; Hill, W. S.; Dixon, R. A. Sigal, I. S.; J. Biol. Chem .1988, 264, 2307.

63. Pearl, L. H.; Taylor, W.R.; Nature 1987, 329, 351.

64. Weber, I. T.; Miller, M.; Jaskolski, M.; Leis, J.; Skalka, A. M.; Wlodawer, A.; Science 1989, 243, 928.

65. Miller, M.; Schneider, J.; Sathyanarayana, B. K.; Toth, M.V.; Marshall, G. R.; Clawson, L.; Selk, L.; Kent, S. B.; Wlodawer, A.; Science 1989, 246, 299.
66. Margolin, N.; Heath, W.; Osborne, E.; Lai, M.; Vlahos, C.; Biochem. Biophys. Res. Commun. 1990, 167, 554.

67. Hyland, L. J.; Tomaszek, T. A.; Meek, T. D.; Biochemistry 1991, $30,8454$. 68. Moore, M. L.; Dreyer, G. B.; Perspect. Drug Discovery Des. 1993, 1, 85.

69. Fitzgerald, P. M. D.; McKeever, B. M.; VanMiddlesworth, J. F.; Springer, J. P.; Heimbach, J. C.; Leu, C.-T.; Werbert, W. K.; Dixon, R. A. F.; Darke, P. L.; J. Biol. Chem. 1990, 265, 14209.

70. Richards, A. D.; Roberts, R. F.; Dunn, B. M.; Graves, M. C.; Kay, J.; FEBS Lett. 1989, 247, 113.

71. Abdel-Meguid, S. S.; Med. Res. Rev. 1993, 13, 731.

72. Ren, S.; Lien, E. J.; Prog. Drug Res. 1998, 51, 1.

73. Erickson, J.; Neidhart, D. J.; VanDrie, J.; Kempf, D. J.; Wang, X. C.; Science 1990, 249, 527.

74. Dreyer, G. B.; Boehm, J. C.; Chenera, B.; DesJarlais, R. L.; Hassel, A. M.; Biochemistry 1993, 32, 937

75. Kempf, D. J.; Marsh, K. C.; Denissen, J. F.; Mcdonald, E.; Vasavadona, S.; Proc. Natl. Acad. Sci. U.S.A. 1995, 92, 2484.

76. Miller, M., Schneider, J., Sathyanarayana, B. K.; Toth, M. V.; Marshall, G. R.; Science 1989, 246, 1149.

77. Swain, A. L.; Miller, M. M.; Green, J.; Rich, D. H.; Schneider, J.; Kent, S. B.; Wlodawer, A.; Proc. Natl. Acad. Sci. U.S.A. 1990, 87, 8805.

78. Lam, P. Y.; Jadhav, P. K.; Eyermann, C. J.; Hodg, C. N.; Ru, Y.; Science 1994, 263, 380.

79. Hodge, C. N.; Aldrich, P.; Bacheler, L. T., Chang, C.-H.; Eyerrmann, C. J.; Chem. Biol. 1996, 3, 301.

80. Engelman, A.; Englund, G.; Orenstein, J. M.; Martin, M. A.; Craige, R.; J. Virol. Methods 1995, 69, 2729.

81. Brown, P. O.; Curr. Top. Microbiol. Immunol. 1990, 157, 19.

82. Pommier, Y.; Marchand, C.; Neamati, N.; Antiviral Res. 2000, 47, 139.

83. Dyda, F.; Hickman, A. B.; Jenkins, F. M.; Craigie, R.; Davies, D. R.; Science 1994, 266, 1981.

84. Hazuda, D.; Blau, C. U.; Felock, P.; Hastings, J.; Prmanik, B.; Wolfe, A.; Bushman, F.; Farnet, C.; Goetz, M.; Willians, M.; Antiviral Chem. Chemother. 1999, 10, 63.

85. Pommier, Y.; Pilon, A. A.; Bajaj, K.; Mazumder, A.; Neamati, N.; Antiviral Chem. Chemother. 1997, 8, 463.

86. Golgur, Y.; Craige, R.; Cohen, G. H.; Fujiwara, T.; Yoshinaga, T.; Fujishita, T.; Sugimoto, H.; Endo, T.; Murai, H.; Davies, D. R.; Proc. Natl. Acad. Sci. U.S.A. 1999, 96, 13040.

87. Hazuda, D. J.; Felock, P.; Witmer, M.; Wolfe, A.; Sitllmock, K.; Grobler, J. A.; Espeseth, A.; Gabryelski, L.; Schleif, W.; Blau, C.; Miller, M. D.; Science 2000, 287, 646

88. Drake, R.; Neamati, N.; Hong, H.; Pilon, A. A.; Sunthankar, P.; Hume, S. D.; Milne, G. W. A.; Pommier, Y.; Proc. Natl. Acad. Sci. U.S.A. 1998, 95 , 4170 .

89. Taktakishivli, M.; Neamati, N.; Pommier, Y.; Nair, V.; J. Am. Chem. Soc. 2000, 122, 5671 .

90. Neamati, N.; Hong, H.; Owen, J. M.; Sunder, S.; Winslow, H. E.; Christensen, J. L.; Zhao, H.; Burke, T. E.; Milne, G. W. A.; Pommier, Y.; J. Med. Chem. 1998, 41, 3202.

91. Mitsuya, H.; Popovic, M.; Yarchoan, R.; Matsushita, S.; Gallo, R. C.; Broder, S.; Science 1984, 226, 172.

92. Schols, D.; Baba, M.; Pouwels, R.; De Clercq, E.; J. Acqir. Immune Defic. Syndr. 1989, 2, 10.

93. De Clercq, E.; J. Med. Chem. 1995, 38, 2491.

94. De Clercq, E.; Clin. Microbiol. Rev. 1995, 8, 200.

95. Kuipers, M.; Huisman, J. G.; Swart, P. J.; Pauwels, R.; De Clercq, E.; Meijer, D. K. F.; J. Acqir. Immune Defic. Syndr. Hum. Retrovir 1996, 11, 419.

96. Mayaux, J. F.; Bousseau, A.; Pauwels, R.; Huet, T.; Henin, Y.; Deru, N. E. M.; Soler, F.; Poujade, C.; De Clercq, E.; Le Pecq, J-B.; Proc. Natl. Acad. Sci. U.S.A. 1994, 91, 3564.

97. Chen, C. H.; Matthews, T. J.; McDanal, C. B.; Bolognesi, D. P.; Greenberg, M.L.; J. Virol. Method 1995, 69, 3771.

98. De Clercq, E.; Yamamoto, N.; Pauwels, R.; Balzarini, J.; Witvrouw, M.; De Vreese, K.; Debyser, Z.; Rosenwirth, B.; Abrams, M.; Antimicrob. Agents Chemother. 1994, 38, 668.

99. Schols, D.; Este, J.; Henson, G.; De Clercq, E.; Antiviral. Res. 1997, 35, 147.

100. Witvrouw, M.; Balzarini, J.; Pannecouque, C.; Jhaumeer-Llaullo, S.; Este, J.; Schols, D.; Cherepanov, P.; Schimit, J.-C.; Debyser, Z.; Vandamme, A. M.; Desmyter, J.; Ramadas, S. R.; De Clercq, E.; Antimicrob. Agents Chemother. 1997, 41, 262

101. Kira, T.; Hashimoto, K. I.; Baba, M.; Okamoto, T.; Shigueta, S.; Antiviral Res. 1996, 32, 55

102. Levy, J. A.; Guthrie, J.; Schinazi, R. F.; Science 1996, 271, 670. 